https://doi.org/10.48009/2_iis_2008_227-231

\title{
CORPORATE SOCIAL NETWORKING
}

\author{
James Sena, California Polytechnic State University San Luis Obispo, jsena@calpoly.edu \\ Mark Sena, Xavier University, sena@xavier.edu
}

\begin{abstract}
Social networking web sites such as Myspace and Facebook have become an extremely popular method of communication, particularly among younger people. Recently organizations have recognized the potential value of using social networking applications within a corporate environment. This study examines the current state of corporate use of social networking by examining existing academic and practitioner literature on this subject and suggests that future research focus on the commonalities and differences between social networking in organizations and the body of research that has focused on group decision support systems and related research areas.
\end{abstract}

Keywords: Social Networking, Intranets, Groupware

\section{INTRODUCTION}

Social networking has been called a variety of things from "the next bubble" to" the next big thing" in software, and it is being applied to all types of personal and business interaction challenges, including getting a date, landing a job, and making a deal. Although some may disagree about the significance of the buzz being created around it, the reality is that social networking vendors are attracting investment capital, and the potential market opportunity is exciting. With very broad applicability, social networking has attributes that suggest it is a solution looking for a problem, and that aspect more than any other squarely positions it as an early adopter technology [1].

The idea behind social networking is simple introductions, regardless of the circumstance, are better and more likely to achieve hoped for results if they are made by a friend or acquaintance rather than out of the blue. With the Internet, e-mail, fast computers, and almost limitless storage capacity available to the desktop user, all that has changed, and the primary limitation to social networking now is finding a business model that can help its sponsors make money. Differences are becoming apparent between the uses of social networking for personal contacts and its uses for business. In general it takes more planning and strategy for social networking to be used successfully in business than in finding a date. And when considering the methods for its use, enterprises are discovering that successful selling using social networking requires much forethought and development of tactics that go well beyond simply contacting a lead.

\section{SOCIAL NETWORKING AT THE CORPORATE LEVEL}

As college students accustomed to finding each other on Facebook and MySpace graduate and begin their working careers [3], the business world is becoming aware of their social networking habits and perhaps incorporating them into their daily work world. A handful of startups have launched social networking services to business users and to companies, hoping that new workers will use them to find customers and contacts the way they once used these sites to find dates. Some market their services to professionals (e.g., Visible Path Corp and .Ryze.com [14], [9]). Others market a social network business service to companies to use for collaboration and sales leads (e.g.., LinkedIn) [8] and "editable" Web sites for collaboration, using networking software code (eg., Socialtext Inc) [12].

Just as with the dot.com boom time it is not certain whether these collaborative business models can make their approaches work in contrast to the success of the personal social network. There is strong evidence that they are being deployed at many large firms. IBM Corp.'s San Jose research center created an in-house social network, called Fringe, connecting individuals in existing but dispersed networks [6]. This started as an experiment by computer science researchers at the IBM Almaden Research Center to see how social networking 
might be used in a corporate setting. Programmers designed a posting, tagging and networking component to IBM's employee directory so that the 330,000 employees spread around the world could find out more about each other when looking for collaborators or in-house expertise. Steve Cousins, senior manager of userfocused systems research who worked on the project, noted that it has caught on, and that 10,000 IBM workers use the corporate-wide social network to look each other up and find out more about each other.

IBM also introduced Atlas for Lotus Connections, a corporate social networking visualization and analysis tool [5]. IBM Atlas for Lotus Connections is designed to help organizations maximize their investment in social software by answering questions such as who the key experts are on a given topic, how they are connected, and whom a user's contacts know that they do not. Developed by IBM Research, Atlas has four Web 2.0-based components -- My Net, Find, Reach and Net. These components help users spot the important connections and the relationships between various groups and navigate their personal and corporate networks.

Another software company (Visible Path) offers a Web-based software service making use of inhouse company networks and employees' other networks, such as those of former co-workers [14]. Their software platform uses social network analysis to algorithmically expand networks of possible sales leads or investment banking contacts. The software essentially replaces cold calls through connections between corporate networks and other linked networks, using the science of social network analysis to draw the most "visible" path to a sales lead or contact.

Online social networking increases the density of connections among individuals to drive business value. A Corporate Social Network is a collection of social networks, among which employees and other corporate constituents may interact through their own, individual profiles [10]. These profiles must be portable and able to collect and amalgamate information from that individual's interactions and knowledge sharing among all of his or her associated corporate networks. These networks are secure and private, open only to those constituencies identified by the enterprise. The connections fostered through
Corporate Social Networks are anchored in affinity and beneficial to individual members through the information they are able to obtain and share, creating knowledge capital that becomes attached to their profile and is visible to other network members. Corporate Social Networks are used primarily to build trust and share knowledge on a peer to peer basis rather than through documents subject to information obsolescence. Network members share knowledge in real-time, in effect creating a living corporate knowledge map within the network.

While many organizations have banned the use of consumer social networking sites such as MySpace and Facebook, a recent study by SelectMinds [10] revealed that private, secure Corporate Social Networks can provide substantial savings for organizations. The study examined the financial contributions of CSN solutions in 60 leading, global organizations. The report revealed that a better connected workforce through CSN technology can yield significant financial contributions to organizations. Key findings of the study include:

- $10.3 \%$ increase in Productivity Contributions;

- $8.8 \%$ increase in Retention Contributions: and,

- $\quad 11.7 \%$ increase in New Business.

Organizations that build and foster personal connections through Corporate Social Networking technology can help break down silos, align corporate objectives and better engage current and former employees.

A sampling of corporate America's top IT executives revealed that many corporations do not have formal policies in place to manage and thus prevent data breaches/network attacks arising from employee social networking, such as instant messaging and surfing social community sites like MySpace.com. The survey was conducted at the Storage Networking World Conference [13], an event designed specifically for IT executives and managers. As online social networking has increased with popular sites such as MySpace.com and Second Life as well as the use of instant messaging technology, IT executives are faced with a growing concern of protecting their computer networks from viruses and other attacks that can penetrate an IT enterprise from them. 
Two-thirds of the conference attendees said their companies had no formal social networking policy in place. Of the 33 percent that did have policies in place, 77 percent said their policies covered "selective blocking" while 23 percent said they blocked all external networking. Other results addressed encryption and computer network downtime. About 54 percent said their companies had no encryption, while 29 percent only encrypt laptops. About 8 percent encrypt all their company's PCs while 9 percent said "everything (USBs, etc.) is encrypted. Also, onethird of the responses said human error was to blame for downtime in IT networks. About 22 percent said IT resource upgrades were a main cause of networks not operating; 15 percent cited "service" failures and 18 percent pointed to network outages.

For all of the technological gains of the past decade, relatively old-fashioned tools such as networking and referrals still drive the process of identifying and hiring qualified candidates. There are some online services that seek to take networking and personal connections from the HR toolbox and combine them with technology. In this sense "Social networking technology" refers to software and web-based services that enable users to leverage their personal relationships for networking, hiring, employee referrals and references. There are some concerns about this practice. Privacy advocates are alarmed by the prospect of software that churns through employees' e-mail. And skeptics remind HR professionals adopting social networking technology that while these services may make generating names of potential hires a snap, transforming those names into candidates remains the real challenge [2].

\section{Business to Business Social Networks}

Silicon Space, $L L C$, [11] a firm specializing in customer-facing software solutions that enable companies to grow their businesses, has a product, SocialSpace, a Business-to-Business (B-to-B) social networking application. Social networking applications are becoming recognized for the value and opportunity they bring to the business landscape, changing the way many organizations do business. Social applications provide a new forum for businesses to facilitate knowledge sharing and collaboration, solicit feedback from internal and external business partners and extend company reach to new channels. By engaging affiliates, partners and customers in an open dialogue, customer retention and satisfaction are improved, increasing revenue and facilitating company growth.

\section{Social Networking - Infrastructure and Methodology Required}

Social networking presents vendors with a double-edged sword for cultivating and leveraging relationships. On one hand, this powerful technology makes it easy for vendors to identify and contact anyone to whom they wish to sell. On the other hand, however, the vendor might get only one chance to introduce an idea to a potential customer or client. Therefore, it is imperative for a good deal of forethought to go into an approach, and systematizing this forethought is what Aberdeen refers to as methodology [1]. In a social networking context, methodology means that the vendor is automatically tasked with the responsibility to have a strategy and a coherent message to deliver prior to making contact. Uncovering strategic relationships is only one part of an integrated methodology designed to increase the likelihood of success in any sales process. From a broad perspective, some parts of the methodology require ongoing efforts by the organization, whereas other parts are specific to a particular deal.

Despite the huge potential returns, few managers adequately invest in developing these kinds of networks and deliberately designing them to foster measurable business results [7]. One reason for this is the misperception that networks, which are essentially self-governing communities, draw their energy from common enthusiasms and a shared sense of purpose and thus cannot be managed. Furthermore, some academics argue that communities of practice are emergent systems that must be allowed to form and evolve without direction. But experience in real-world companies suggests that these entities can and should be actively managed, albeit not with conventional forms of management. Mandating goals and installing individual performance metrics can cause communities of practice to disintegrate, and indiscriminately throwing money (or collaboration software) at them without a clear set of priorities and a way of evaluating success can be equally wasteful. Success comes from applying the same rigor, time, and attention to the "soft issues" of 
designing and managing human connections that managers ordinarily apply to structural decisions about capital investment logistics, and technology.

\section{Building a Social Networking Infrastructure}

An organization can do several things on an ongoing basis to ensure that it is well positioned to maximize its social networking strategy. Without necessarily creating a burden for itself, a company must define an infrastructure that will ensure the security and access control of its contact data, maintain the quality of that data, properly integrate all systems to afford a 360degree view of clients, and lastly, be easily accessed by the user.

Strengthening an organization's capacity for collaboration requires a combination of long term investments - in building relationships and trust, in developing a culture in which senior leaders are role models of cooperation - and smart near-term decisions about the ways teams are formed, roles are defined, and challenges and tasks are articulated. Practices and structures that may have work well with simple teams at one location and where everyone knew one another are likely to lead to failure when teams grow more complex. Most of the factors that impede collaboration today would have impeded collaboration at any time [4]

\section{Implications of Social Networking for Researchers}

As social networks have become prolific, the topic has drawn interest from academic researchers from various disciplines. Much of the focus, given the vast popularity of Facebook and MySpace has been on the implications of the use of these sites on individuals and society. While there has been little research on the use of social networks at the corporate level, there are many related technologies that have similar functionality and research issues.

Social Networks are essentially communication tools that allow users to share information or media with selected individuals, with groups of individuals sharing common interests, with an entire network of users, etc., Social Networks also provide tools for collaboration to help users on the network organize and create information.
While the specific nature of social networking applications are relatively new to corporations, the aforementioned functions they serve have been around for years in various forms. Applications such as groupware, group decision support systems, knowledge management systems, email, intanets and extranets, portals, and blogging tools are among the various technologies that can serve similar purposes in the workplace as social networking applications. Each of these tools has been studied to varying degrees in academic literature. Thus, it is important to examine social networking in the workplace using the foundation that has been formed by research on these related technologies.

\section{CONCLUSIONS}

Social networking has created many new possibilities for individuals and firms seeking to reach out to various marketplaces, and it promises to be an important engine of business productivity in the coming years. As with any new technology, there are appropriate and inappropriate uses for social networking, and results will vary with the way that the technology is applied. Users who take a process centric approach to social networking will fare better than those who "shoot from the hip" when they think about contacting others. In this new market the temptation to use social networking in a random way will be too great a temptation for some to resist, which will undoubtedly lead to a new form of "spam" that gets ignored and deleted without consideration by those for whom messages are intended.

A well-designed social networking strategy and its supporting applications should, to summarize, be able to:

- $\quad$ Respect individual relationships (Users would not permit a system to mine emails, and a company cannot force businesspeople to share what they wish to keep private);

- Enable users to retain control over their relationships - opt out; opt in anonymously; opt in, but not share everything about a relationship; or opt in, but share information with only a select group of people; and,

- Provide mechanisms to ensure relationships will not be abused; 
Research on the use of social networking within a corporate environment should help to explain the factors that drive the success or failure of an organization's ability to achieve these objectives. Past research on related topics such as groupware, group decision support systems, and Intranets and Extranets should be useful in providing a foundation for future research on this emerging issue.

\section{REFERENCES}

1. Aberdeen Group Relationship Capital Management - Going Beyond Social Networking to Sell in Relationship-Based Organizations, An Executive White Paper. January 2004. Aberdeen Group, Inc. http://www.aberdeen.com

2. Berkshire, J. (2005) Social network' recruiting: software and online services help recruiters mine their contacts for candidates and referrals, Society for Human Resource Management, 2005 Gale Group

3. Grady, B. (2008) Corporate America embraces social networking, ANG Newspapers. Information and Learning Company.

4. Gratton, L. and Erickson, T. (2007) Eight Ways to Build Collaborative Teams, Harvard Business Review, November 2007.

5. IBM (2007) IBM Launches Tool to Help Businesses Visualize Social Networks IBM Atlas:

http://www.ibm.com/software/lotus/services /assets.html

6. Krill, P. (2007). IBM research projects cover SOA, Web 2.0. InfoWorld, Jan 31, 2007.

7. Laseter, T and Parker, A.(2006) The Craft of Connection, Strategy + Business, Issue 44, Fall 2006.

8. Linked In, http://www.linkedin.com

9. Ryze Business Networking, http://Ryze.com

10. SelectMinds (2008) Corporate Social Networking: SelectMinds Benchmarking Study, www.selectminds.com

11. Silicon Space http://www.siliconspace.com/

12. Social Text, http://www.socialtext.com

13. Storage Networking World (2007) Few Top Corporations Establish Formal Policies Limiting Social Networking on the Internet, April $\quad 16 \quad-19$,San Diego. http://www.snwusa.com

14. Visible Path Corporation. http://visiblepath.com 